\title{
The Role of Metacognition and its Interaction on Students' Negative Academic Emotions towards Their Academic Buoyancy and Achievement in Mathematics
}

\author{
Eddiebal P. Layco \\ Senior High School \& Graduate School, Don Honorio Ventura State University, Philippines
}

Received October 3, 2020; Revised November 13, 2020; Accepted December 6, 2020

\section{Cite This Paper in the following Citation Styles}

(a): [1] Eddiebal P. Layco, "The Role of Metacognition and its Interaction on Students' Negative Academic Emotions towards Their Academic Buoyancy and Achievement in Mathematics," Universal Journal of Educational Research, Vol. 8, No. 12A, pp. 7500 - 7510, 2020. DOI: 10.13189/ujer.2020.082534.

(b): Eddiebal P. Layco (2020). The Role of Metacognition and its Interaction on Students' Negative Academic Emotions towards Their Academic Buoyancy and Achievement in Mathematics. Universal Journal of Educational Research, 8(12A), 7500 - 7510. DOI: 10.13189/ujer.2020.082534.

Copyright $@ 2020$ by authors, all rights reserved. Authors agree that this article remains permanently open access under the terms of the Creative Commons Attribution License 4.0 International License

\begin{abstract}
This causal research study generally determined the intervening effect of students' metacognition in terms of cognition, motivation, and behavior on the association of their negative emotions with their academic buoyancy and achievement. Data were obtained from a sample of 1100 students from the different students from chosen Senior High Schools in the Division of Pampanga, Philippines during S.Y. 2018-2019. Results revealed that students' negative academic emotions such as anxiety, anger, boredom, hopelessness and shame predict their capacity to cope up with their difficulties in mathematics as well as their achievement in the subject. Result also showed that the relationship between the student's academic buoyancy and achievement is partially intervened by metacognition. This implies that students' ability to bounce back causes them to improve their grades because of their academic cognition, motivation, behavior, and some other factors. Furthermore, the impact of negative academic feelings on students' academic buoyancy and achievement is being moderated by metacognition which indicates that metacognition does not affect the achievement of students who have high levels of negative academic emotions in mathematics in terms of their grades. On the other hand, students who have low levels of negative academic emotions in their grades given that they have higher levels of metacognition and academic buoyancy achieve higher grades in mathematics. With these results, it was recommended that to lessen the impact
\end{abstract}

of negative feelings such as uneasiness and hopelessness on achievement, educator should consider metacognitive strategies for their students to be buoyant and finally increase the chances to achieve academic success.

Keywords Negative Academic Emotions, Academic Buoyancy, Metacognition, Academic Achievement

\section{Introduction}

The connection between the academic competence of the students especially in mathematics and the negative academic emotions was shown in few studies. The experimental data about the rationale on when and why this relationship happened do not exist. Anxiety has been the focused of studies about students' negative emotion and its association with achievement. However, study concentrating on the other negative emotions experienced by learners has given conceptual and experimental attention.

There are many students' emotions to be considered in the classroom aside from anxiety [1]. Emotions such as anger, boredom, enjoyment, hopelessness, shame, and pride can influence students' learning in different ways. Moreover, these can be affected by learning environment factors, students' individual differences, and external 
factors [2]. Variety of emotions and their causes, teachers should have a knowledge on how to moderate the academic emotions of students especially their negative emotions such as anger, anxiety, boredom, hopelessness, and shame since studies showed that these were negatively correlated to their performance. This implies that the higher the level of anxiety, anger, hopelessness, shame, and boredom of the students, the lower their performance in Mathematics wherein negative emotion becomes a barrier to achieving goals. It is the low capacity of an individual to be in contact with his or her own emotions [3].

Previous studies indicated that students in terms of their level of mathematics achievement, experienced different levels of academic emotions either positive or negative [4], [5]. Anxiety, anger, and boredom were the most common revealed negative academic emotions to be found among poor performing students.

There are many emotions and feelings that can be experienced by the students inside the classroom [6]. As stated that the above mentioned negative emotions may have an impact to the students and to their acquisition of knowledge.

Students with poor achievement results in mathematics are more likely have negative feelings like anger, boredom, and uneasiness. It was implied in the prior researches that the emotion felt by the students whether it is positive or negative is based on their level of achievement in mathematics [8], [9], [10].

Teachers are aware that some feelings like uneasiness in mathematics may affect the cooperation of the students during discussion. This emotion may also have a negative effect in the performance of the students during examination. However, in the study of Trezise and Reeve [11], they stated that there are some students who can handle their anxiety in mathematics, others decline their cognitive capability. This means that students are not affected similarly with negative anxiety.

Mathematics failure due to uneasiness or worry was not experienced by students who exhibited activation of brain areas related to motivation and cognitive control as implied by the neuroscience [12]. In order for teachers to know more about the feelings and emotions of their students, doing some research or investigation on how they are able to acquire knowledge despite having negative emotions may help.

The models which include the impact of feelings on the acquisition of knowledge and performance are incorporated in Pekrun's control-value theory [13]. Recently, achievement emotions were found to have an essential effect on students' achievement goals and academic achievement. Additionally, it was learned that negative feeling like anxiety predicted low achievement, while positive feelings like satisfaction, hope, and self-respect predicted high achievement.

This study also focuses on the association among students' negative emotions, academic buoyancy and achievement. The specific negative emotions stated in this study are anger, anxiety, shame, hopelessness, and boredom as studied to be five of the ten academic emotions of Filipino students [14]. The ability to win against the challenges, hardships, and problem which happened in life is referred to as academic buoyancy. It is also defined as the capability of the students to face and overcome the challenges and difficulties that usually happened in school (e.g., failing grades, meeting and beating deadlines, pressure during examination, difficult schoolwork.). This served as a construct showing the daily academic strength within a positive psychology [15].

The students' capability to be buoyant when it comes to the difficulties in academics is related with the significant motivational and emotional outcomes as demonstrated by research. Emotional outcomes involve (e.g., lower anxiety $[16,17]$ and motivational outcomes involve (e.g., greater persistence [18]).

Moreover, the evaluation on the ability of an individual to handle setback is referred to as buoyancy, considering the feelings that are connected to a set of psychological procedures that are encountered as an answer to a circumstance (e.g., fear, worries, impulses to act)[ 19], [20].

Furthermore, it was revealed that students who experienced higher anxiety scored lower while students with high in buoyancy and low in anxiety scored higher. This was revealed in the research about the connection between buoyancy and achievement related to anxiety [21]

In this study, in order to increase the buoyancy literature, the researcher examines the tasks played by other factors. This only shows that negative emotion like anxiety predicts students' performance as well as their ability to become buoyant and resilient on their task in Mathematics. It also examines the role of metacognition on students' negative emotions in association with their buoyancy and achievement. The array of techniques, knowledge, and procedures that appraise, observe, and regulate cognition is called metacognition [21]

The task of negative emotion was not addressed in some researches on the use of metacognitive learning techniques in academic environment. However, it was found in the previous studies that the possibility that the student will utilize a type of metacognitive strategies specifically the cognitive strategies that result in deeper, elaborative processing of information was lessen by the negative feeling [22]. Specifically, Turner, Thorpe, and Meyer [23] found that deeper used techniques were negatively correlated with negative emotions. Therefore, it is anticipated that deeper cognitive techniques are not utilized by students who have negative feelings because these techniques need more concentration and involvement. Contradictory, students who are happy and have positive feelings are more likely to have deeper techniques and more engagement. For the role of negative emotions on students' metacognition, studies showed 
significant relationship between these variables.

In the study of Tajrishi, et al. [24] about metacognitive beliefs and negative emotions, it was found out that negative feelings such as uneasiness and depression were positively and significantly connected with metacognition (cognitive confidence and necessity to regulate account, favorable feelings about anxiety, negative feelings toward anxiety about risk and uncontrollability). Furthermore, it was shown that students with lower scores have more negative feelings just like the students who have higher scores in metacognition scale which measures their metacognitive beliefs developed by Wells and Cartwright-Hatton. Additionally, numerous studies showed causal link between students' metacognition and achievement. Results also showed that in solving mathematical problems during examination, students experience difficulties [25]

Students easily give up on solving mathematical problems because they think that they are not doing the right way and because of committing mistakes in computation. Additionally, students have difficulty in determining when to apply a particular content knowledge despite having information in solving problems. In order to surpass these problems, students must train themselves with metacognitive techniques.

Based on the aforementioned literature and studies, the researcher aims to weaken the effect of students' negative academic emotions towards their ability to overcome minor academic setbacks and achievement in their Mathematics subject. With this purpose, the researcher hypothesized that metacognition may weaken the effect of students' negative academic emotions on their academic buoyancy and achievement.

\subsection{Objectives}

\section{General and Specific Objectives}

The researcher of the study generally aimed to test the intervening effect of students' metacognitive strategies on the association of negative emotions with their academic buoyancy and achievement. Specifically, it answered the following objectives: (1) to assess students' negative academic emotions (anger, anxiety, boredom, hopelessness, and shame), metacognition (cognition, motivation, and behavior), academic buoyancy and mathematics achievement, (2) to determine the inter-correlations among the said variables, (3) to investigate the moderating role of metacognition in the association of students' negative emotions in their academic buoyancy and mathematics achievement, and (4) to determine the mediating role of students' metacognition on the connection between their academic buoyancy and achievement.

\subsection{Conceptual Framework}

The study is anchored on control value and metacognitive theories. The paradigm of the study is illustrated in Figure 1.

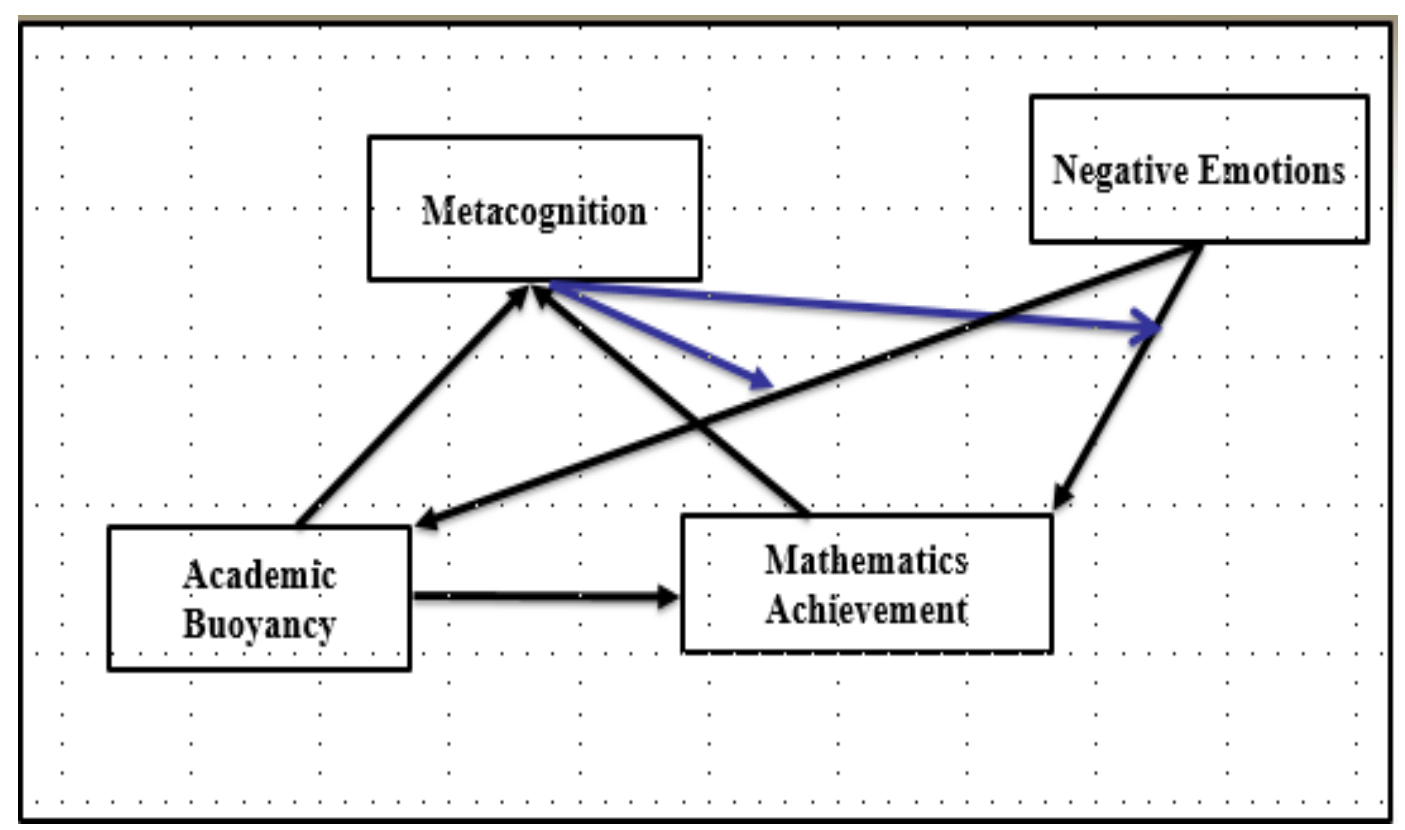

Figure 1. Conceptual Model Depicting the Effect of Students' Metacognition on the Link between Negative Emotions and Academic Buoyancy \& Achievement in Mathematics 


\section{Materials and Methods}

\subsection{Research Design}

The researcher utilized Causal Research design specifically Causal Chain Analysis technique to determine the effects of the intervening variable on the association of predictor and outcome variables in the study.

\subsection{Participants}

The respondents in this study were 1100 selected students enrolled from 22 Senior High Schools in the Division of Pampanga during the second semester of S.Y. 2018-2019 taking Probability and Statistics. Power analysis was utilized to calculate the sample size with the accepted minimum significance level $(\alpha)$ of 0.05 and accepted minimum level of power $\beta$ of 0.80 [26]. The effect size of 0.25 was calculated based on Cohen's d formula, a common measure of estimating the effect size. In selecting the respondents of the study, simple stratified sampling technique was utilized. This was used to guarantee a fairly equal representation of sample respondents from 22 Senior High Schools offering STEM strand.

\subsection{Instrument}

\subsubsection{Academic Buoyancy}

Four items about the different pressures in schoolwork were included in the Academic Buoyancy Scale (ABS) [27] ("I am good in dealing with setbacks in my experiences in mathematics"; "I think I'm good at dealing with my work in mathematics"; "I don't let bad grades affect my self-confidence in mathematics"). Items were rated by the respondents from 1 (Strongly Disagree) to 5 (Strongly Agree). The scale had an adequate internal consistency of Cronbach $\alpha$ of 0.83 .

\subsubsection{Metacognition}

It evaluates the metacognitive beliefs using a 30-item self-report measure proposed by Wells \& Cartwright-Hatton [28]. In evaluating the different elements of metacognition which involves understanding, preparing, and monitoring, this instrument possessed a good reliability and validity [29]. It was showed by the factor analysis that the instrument calculated metacognitive knowledge and regulation of cognition. Moreover, this instrument reached the desired internal consistency of 0.87 .

\subsubsection{Negative Academic Emotions}

Using the Achievement Emotions Questionnaire (AEQ-M), Five emotions: anger, anxiety, boredom, hopelessness, and shame) were evaluated [29]. The emotional experiences of the students in probability and statistics subject including their experiences in school, in acquiring knowledge, and during examinations are the items adopted from AEQ-M. In this article, only the parts included in the anger scales were analyzed among the 60 items pertaining to eight diverse academic emotions in the AEQ-M, (9 items, e.g., "I get angry because the material in math is difficult"), anxiety (15 items, e.g., "When taking the math test, I worry I will get a bad grade" ), hopelessness (6 items, e.g., "I keep thinking that I will never get good grade in mathematics) and shame (8 items, e.g., "I am ashamed that I cannot answer my math instructor's question well."). Using a 5-point scale ( $1=$ strongly disagree; $5=$ strongly agree) participants were asked to tell their agreement in each item. For the sample, every scale has an acceptable internal consistency (anger: Cronbach $\alpha=0.82$, anxiety: $\alpha=0.87$, shame: $\alpha=0.75$, hopelessness: $\alpha=0.80$ ).

\subsubsection{Achievement}

Achievement will be assessed in terms of students' previous final grade in Mathematics which will be converted into a 5-point Likert Scale in which range of grades it falls.

\subsection{Procedure}

The researcher used the five questionnaires in gathering first-hand information from the respondents. Before the copies of the questionnaires were distributed to the respondents, the researcher sought first the permission of the School Superintendent of the Division of Pampanga. When the letter was approved, the researcher visited the target schools to coordinate with the school heads and teachers. The researcher introduced himself to the respondents and assured them that the principal and the academic chairman of the Senior High School department of respective schools gave him a permission to gather data. Moreover, the researcher explained the purpose of the study. The researcher secured a Notice of Non-disclosure agreement and Data Privacy Notice. The respondents were given the freedom to stop participating if they have personal reasons and they need not worry about the consequences of their decision. Furthermore, the instructions were given to the respondents in answering the questionnaires and the time it would take them to finish answering. The data were gathered from Sept 10 to Sept 14, 2018.

The data gathered were tallied, tabulated, processed and treated using Statistical Package for Social Sciences (SPSS) with Process Macro v.16 of Andrew F. Hayes.

\section{Results and Discussions}

\subsection{Descriptive and Inter-Correlations Statistics}

The descriptive and inter-correlational statistics for 
students' metacognition, negative academic emotions, academic buoyancy and achievement are shown in Table 1.

As can be observed on the table, students have high level of metacognitive skills in terms of academic cognition and academic motivation, and average level of academic behavior. In general, they have high level of metacognition and both high levels of academic buoyancy and achievement in mathematics have weighted means of 3.86 and 4.07 respectively. For their negative emotions, students have an average level of anxiety and hopelessness while low levels of anger, shame, and boredom in the said subject.
Table 1. Descriptive Analysis of Students' Level of Metacognition, Negative Academic Emotions, Academic Buoyancy, and Mathematics Achievement

\begin{tabular}{|c|c|c|c|}
\hline \multicolumn{4}{|c|}{ Descriptive Analyses } \\
\hline Variables & Mean & SD & Level \\
\hline Metacognition: & & & \\
\hline a. Cognition & 4.05 & 0.73 & High \\
\hline b. Motivation & 4.00 & 0.67 & High \\
\hline c. Behavior & 3.36 & 0.72 & Average \\
\hline $\begin{array}{c}\text { Negative Academic } \\
\text { Emotions: }\end{array}$ & & & \\
\hline d. Anger & 2.30 & 0.68 & Low \\
\hline e. Anxiety & 2.65 & 0.75 & Average \\
\hline f. Shame & 2.33 & 0.74 & Low \\
\hline g. Hopelessness & 2.51 & 0.64 & Low \\
\hline h. Boredom & 2.39 & 0.45 & Low \\
\hline i. Acad. Buoyancy & 3.86 & 0.89 & High \\
\hline j. Math Achievement & 4.07 & 0.78 & High \\
\hline
\end{tabular}

Table 2. Inter-correlations of Variables of the Study

\begin{tabular}{|c|c|c|c|c|c|c|c|c|c|}
\hline \multirow{2}{*}{ Variables } & \multicolumn{9}{|c|}{ Correlation Analyses } \\
\hline & (b) & (c) & (d) & (e) & (f) & (g) & (h) & (i) & (j) \\
\hline a. Cognition & $0.57^{*}$ & $0.63^{*}$ & $-0.41^{*}$ & $-0.47^{*}$ & $-0.39 *$ & $-0.43^{*}$ & $-0.50 *$ & $0.57 *$ & $0.63 * *$ \\
\hline b. Motivation & - & $0.62 *$ & $-0.43^{* *}$ & $-0.57 * *$ & $-0.41^{*}$ & $-0.45^{*}$ & $-0.49 *$ & $0.72^{* *}$ & $0.77^{* *}$ \\
\hline c. Behavior & & - & $-0.40^{*}$ & $-0.52 * *$ & $-0.49 *$ & $-0.43^{*}$ & $-0.47^{*}$ & $0.53 *$ & 0.60 \\
\hline d. Anger & & & - & $0.67 *$ & $0.60 *$ & $0.53^{*}$ & $0.57^{*}$ & $-0.43^{*}$ & $-0.47^{*}$ \\
\hline e. Anxiety & & & & - & 0.63 & $0.60 *$ & $0.62 *$ & $-0.67 * *$ & $-0.72 * *$ \\
\hline f. Shame & & & & & - & 0.60 & $0.69 *$ & $-0.49 *$ & $-0.47 *$ \\
\hline g. Hopelessness & & & & & & - & $0.57^{*}$ & $-0.57^{* *}$ & $-0.60 * *$ \\
\hline h. Boredom & & & & & & & - & $-0.63^{* *}$ & $-0.57 * *$ \\
\hline i. Acad. Buoyancy & & & & & & & & - & $0.78^{*}$ \\
\hline j. Math Achievement & & & & & & & & & - \\
\hline
\end{tabular}


The expected negative relationship of negative academic emotions to students' academic buoyancy and achievement in Mathematics was confirmed on Table 2. Further, positive relationship exists among students' metacognition, academic buoyancy, and achievement. This is in support to the study of Young and Fry [30] in which they reported that metacognition influenced students' academic achievement. Moreover, knowledge of cognition or knowing how we learn deals with all the concepts which are related to the thinking process [31]. Having a high level of metacognitive awareness on how students learn will help them acquire and understand Math concepts and ideas easily. For the connection of students' academic buoyancy to their academic emotions and achievement, research revealed that students' ability to be buoyant amidst academic challenge and setback is associated with necessary motivation such as greater determination and lower anxiety which in turn affect academic achievement [32]. Lastly, Villavicencio and Bernardo [33] found in their study that negative emotions influenced Filipino students' achievement in Trigonometry, one of the fields in mathematics. The implication of this results only shows that the more the chances that students bounce back amidst all the trials and challenges they face in their mathematics is directly related to their achievement in the subject. Further, the way of controlling their negative academic emotions and enhancing their cognition, motivation and behaviour towards the said subject has something to do with their ability to be academically buoyant which can be associated to their achievement.

\subsection{Moderating Effects of Students' Metacognition on their Negative Academic Emotions and Academic Buoyancy}

Analysis of data shown in Table 3 only illustrates that metacognition predicted the academic buoyancy of the students $(\beta=0.25, \mathrm{SE}=0.30, \mathrm{p}$-value $<0.000)$ and the same is true with all the negative academic emotions: Anger $(\beta=-0.16$, SE of $\beta=0.05$, $p$-value $<0.002)$; Anxiety $(\beta=-0.26$, $\mathrm{SE}=0.07, \mathrm{p}$-value $<0.000)$; Shame $(\beta=-0.11, \mathrm{SE}=0.07$, $\mathrm{p}$-value $<0.000), \quad$ Hopelessness $\quad(\beta=-0.20, \quad \mathrm{SE}=0.03$, $\mathrm{p}<0.000)$, and Boredom $(\beta=-0.32, \quad \mathrm{SE}=0.06$, p-value $<0.000$ ). The interaction of metacognition to all negative academic emotions predicting academic buoyancy is said to be significant. The table presented that the 19 effect of negative academic emotions lessened when interacted to metacognition.

Table 3. Academic Buoyancy Predicted from the Interaction of Negative Academic Emotions and Metacognition

\begin{tabular}{cccc}
\hline Predictor & $\boldsymbol{\beta}$ & $\begin{array}{c}\text { Std. } \\
\text { Error }\end{array}$ & p-value \\
\hline Anger & -0.16 & 0.05 & 0.002 \\
Metacognition** & 0.25 & 0.30 & 0.000 \\
Anger x Metacognition & -0.10 & 0.03 & 0.000 \\
Anxiety & -0.26 & 0.07 & 0.000 \\
Metacognition** & 0.25 & 0.30 & 0.000 \\
Anxiety x Metacognition & -0.14 & 0.02 & 0.000 \\
Shame & -0.11 & 0.07 & 0.000 \\
Metacognition** & 0.25 & 0.30 & 0.000 \\
Shame x Metacognition & 0.20 & 0.03 & 0.000 \\
Hopelessness & -0.20 & 0.03 & 0.000 \\
Metacognition** & 0.25 & 0.30 & 0.000 \\
Bopelessness x Metacognition & -0.12 & 0.02 & 0.000 \\
Boredom & -0.32 & 0.06 & 0.000 \\
Metacognition** & 0.25 & 0.30 & 0.000 \\
Boredom x Metacognition & -0.15 & 0.08 & 0.000 \\
\hline
\end{tabular}

Dependent Variable: Academic Buoyancy

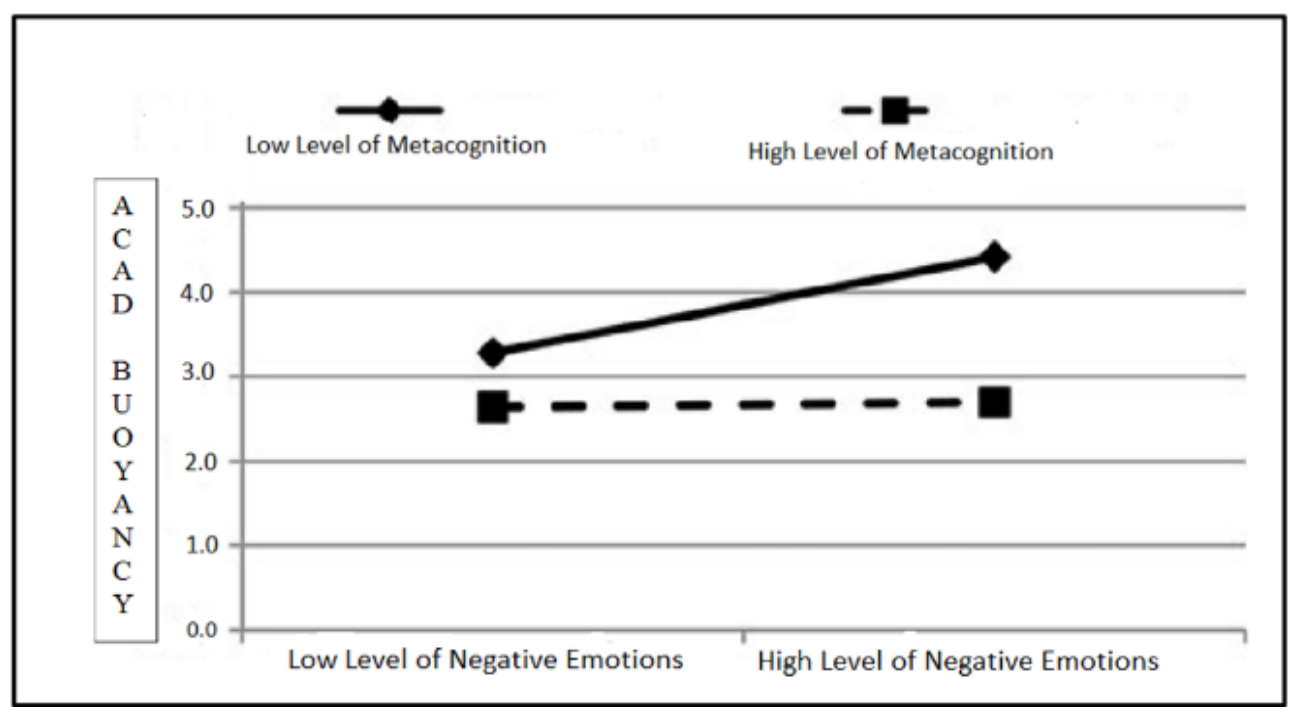

Figure 2. Interaction between Negative Academic Emotions and Metacognition Predicting Academic Buoyancy 
The final marks of students with high levels of negative academic emotions were not influenced by their levels of metacognition. In contrast, for students who have low levels of negative academic emotions, levels of academic buoyancy were higher for those who have higher levels of metacognition. This only shows that metacognition moderated the effect of negative academic emotions to the ability of the students to face all the challenges, trials, and difficulties in Mathematics.

The result supports the study of Martin and Marsh [34] which stated that in education, negative feelings such as uneasiness lessen the capability of the students to acquire knowledge. The academic buoyancy of the students must be seen as a positive psychology version of strength. More positive feelings are shown by buoyant individuals than less buoyant. Buoyant students tend to have higher achievement. Additionally, in order for them to recover from difficult experiences immediately, they avoid negative feelings and make use of the positive feelings than the less buoyant [35].

Results also show how all the negative academic emotions are related with lower levels of metacognition and achievement in accordance to early cross-cultural studies [36]. Furthermore, the results reveal that metacognition buffers the negative relationship of students' negative emotions to their achievement in learning. Moreover, Ruthig et al. [37] as cited [38], it was stated that the improvement on the present theoretical proposals about the difficulties of students in acquiring knowledge due to negative academic emotions was provided by the decreasing effect of negative academic emotions.

\subsection{Moderating Effects of Students' Metacognition on their Negative Academic Emotions and Achievement}

Data on Table 4 revealed that negative academic emotions significantly correlated and predicted the achievement of the students in terms of their grades.
Table 4. Mathematics Achievement Predicted from the Interaction of Negative Academic Emotions and Metacognition

\begin{tabular}{cccc}
\hline Predictor & $\boldsymbol{\beta}$ & $\begin{array}{c}\text { Std. } \\
\text { Error }\end{array}$ & p-value \\
\hline Anger & -0.30 & 0.03 & 0.000 \\
Metacognition** & 0.72 & 0.05 & 0.000 \\
Anger x Metacognition & -0.09 & 0.03 & 0.000 \\
Anxiety & -0.30 & 0.02 & 0.000 \\
Metacognition** & 0.72 & 0.05 & 0.000 \\
Anxiety x Metacognition & -0.13 & 0.02 & 0.000 \\
Shame & -0.23 & 0.07 & 0.000 \\
Metacognition** & 0.72 & 0.05 & 0.000 \\
Shame x Metacognition & -0.21 & 0.03 & 0.000 \\
Hopelessness & -0.23 & 0.03 & 0.000 \\
Metacognition** & 0.72 & 0.05 & 0.000 \\
Bopelessness x Metacognition & -0.11 & 0.02 & 0.000 \\
Boredom & -0.30 & 0.04 & 0.000 \\
Metacognition** & 0.72 & 0.05 & 0.000 \\
Boredom x Metacognition & -0.20 & 0.10 & 0.000 \\
\hline
\end{tabular}

Dependent Variable: Mathematics Achievement

Results for negative academic emotions predicting academic achievement were as follows: Anger $(\beta=-0.30$, $\mathrm{SE}$ of $\beta=0.03$, p-value $<0.000)$; Anxiety $(\beta=-0.30, \mathrm{SE}=$ 0.02 , $p$-value $<0.000)$; Shame $(\beta=-0.23, \quad \mathrm{SE}=0.07$, $\mathrm{p}<0.000)$, Hopelessness $(\beta=-0.23$, SE $=0.03, \mathrm{p}<0.000)$, and Boredom $(\beta=-0.30, \mathrm{SE}=0.04, \mathrm{p}<0.000)$. Students' metacognition in terms of their cognition, motivation, and behavior also predicted their achievement in mathematics $(\beta=0.72, \quad \mathrm{SE}=0.05, \mathrm{p}<0.000)$. The interaction of metacognition and negative academic emotions such as anger, anxiety, hopelessness, shame and boredom weakened their effects on students' achievement. This only shows metacognition served as moderator between the relationship of negative emotions and achievement. The interaction between the said variable is shown in Figure 3.

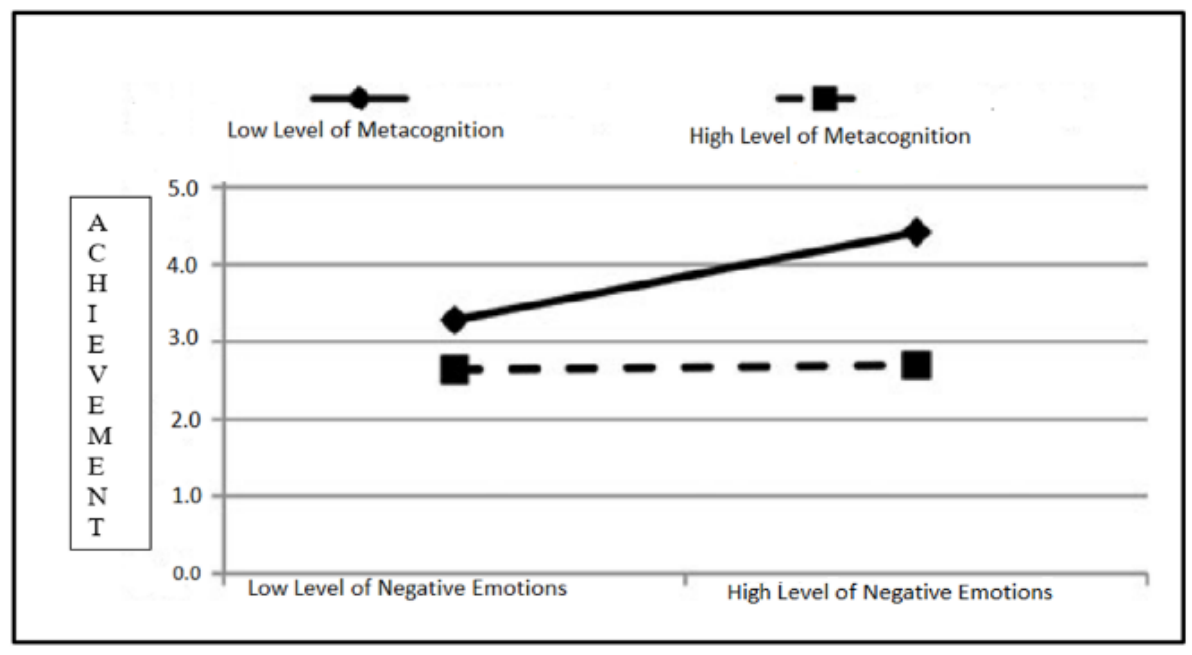

Figure 3. Interaction between Negative Academic Emotions and Metacognition Predicting Achievement 
Metacognition does not affect the achievement of students who have high levels of negative academic emotions in mathematics in terms of their grades. Contrary to the said statement, where students who have low levels of negative academic emotions and higher levels of metacognition, still they can achieve higher grades. The results of the study support the claims of different authors who conducted studies on academic emotions specifically the negative academic emotions because it has a negative academic impact on the academic performance of the students in terms of their grades [39], [40], [41].

According to Dong and Yu (2010), one way to assist the students to maintain their attention in acquiring knowledge is by changing negative emotions into positive. Thus, teachers' ways of improving metacognition in terms of cognition, motivation, and behavior may result to students putting effort in acquiring knowledge, improving creative learning techniques, and assisting students to improve their competence in mathematics. However, levels of motivation and the attention in acquisition of knowledge may be lessened by the negative academic emotions which lead to the utilization of the automatic learning techniques (e.g., repetitive memorizing) of the students [42]. This only implies that teachers should find ways of strengthening the level of metacognition of the students in order for them to lessen the effect of negative academic emotions to students' grades.

\subsection{Mediating Effects of Students' Metacognition in their Academic Buoyancy and Achievement}

Students' metacognition substantially intervenes the connection between academic buoyancy and achievement $(\mathrm{a} * \mathrm{~b}=0.43$, $\mathrm{p}$-value $<.01)$ as presented by the analysis of data. Metacognition in mathematics $(\mathrm{a}=0.84$, $\mathrm{p}$-value $<.01$ ) was affected by the students' academic buoyancy based on the findings, which also have an impact in their mathematics achievement $(\mathrm{b}=0.51, \mathrm{p}$-value $<.01)$ as illustrated in Table 4 and Figure 4.

Table 5. Parameter Estimates of the Mediation of Students Metacognition in the Association between Academic Buoyancy and Mathematics Achievement

\begin{tabular}{ccccc}
\hline Path & $\begin{array}{c}\text { Path } \\
\text { Coeff. }\end{array}$ & p-value & $\begin{array}{c}\text { Effect } \\
\text { Size }\end{array}$ & Remarks \\
\hline $\begin{array}{c}\text { Path a: } \\
\text { AB->MC } \\
\text { Path b: }\end{array}$ & 0.84 & 0.000 & 0.02 & Significant \\
$\begin{array}{c}\text { MC->MA } \\
\text { Path c }\end{array}$ & 0.51 & 0.000 & 0.18 & Significant \\
$\begin{array}{c}\text { AB->MA } \\
\text { a*b: }\end{array}$ & 0.83 & 0.000 & 0.20 & Significant \\
$\begin{array}{c}\text { AB->MC->MA } \\
\text { c'+a*b: } \\
\text { Total Effect }\end{array}$ & 0.43 & 0.000 & 0.00 & Significant \\
\hline
\end{tabular}

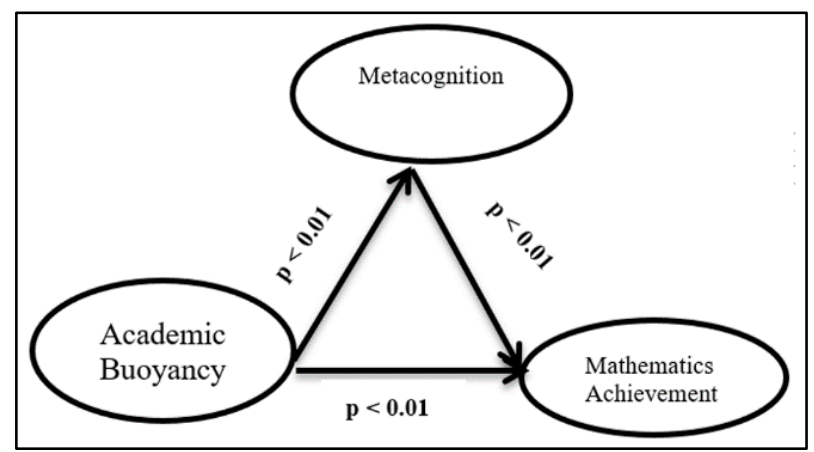

Figure 4. Mediating Role of Students' Metacognition on the link between their Academic Buoyancy and Achievement

The table also shows also the effect size in each path. It shows that the given paths were computed considering normal effect sizes. Moreover, the connection between the students' academic buoyancy and achievement is partly intervened by their metacognition since the relationship between the said variables is still significant after including the effect of the mediating variable. This only means that students' capacity to bounce back in their subject which causes their achievement because of their academic cognition, motivation, behavior and some other external factors. The partial mediation indicating that the association between achievement and academic buoyancy is significant even their metacognition introduced is said to be also significant considering the Sobel test value $(\mathrm{t}=3.75, \mathrm{SE}=0.35, \mathrm{p}<0,01)$.

The result of the study is consistent with the results obtained by You et al [43] which stated that in order to predict achievement and buoyancy independently, the first encounter to these two may not be adequate.

Control discuss a substantial amount of the conflicts in achievement which leads for the buoyancy to clarify little things that is why this happened. The close relationship of achievement and control was shown in research.

Moreover, the relationship between achievement and buoyancy is weak to start with in the absence of the involvement of control [44].

The utilization of early achievement in controlling the setback is unsure. There is no guarantee that the essential adaptive acts which are needed to succeed will be activated. However, how these adaptive actions used may be determined on different procedures. Procedures which are closely connected with achievement may be activated by the assistance of buoyancy. Socio-emotional and motivation factors have the ability to anticipate achievement and buoyancy is very important in dealing with these factors which showed that this interpretation is congruent to other early researches [45].

\section{Conclusions and Recommendation}

The findings of the study give an information about the connection between academic buoyancy and student 
achievement. This also brings out the problems of negative academic emotions on their mathematics achievement. Moreover, it also deals about the issues of academic buoyancy as they emphasized the implicit ability of metacognition of academic cognition, motivation and behavior which aid the students to have a positive output rather than setback. Specifically, the findings point out the significance of the emotions and development of the students in school in order to achieve academic achievement.

This research shows that the learners' negative academic emotions have something to do with the way they bounce back after they've experienced poor grades and difficulties in mathematics. To lessen the impact of negative feeling such as uneasiness and hopelessness on achievement, educator should consider metacognitive strategies for their students to be buoyant and finally increase the chances to achieve academic success.

Parents and teachers should work hand in hand in order for the students to develop their ability to be both resilient and buoyant in facing their mathematics subject, turn negative academic emotions into positive, and improve their performance in the said subject.

Focus and interest must be given emphasis in the study of academic buoyancy and academic emotions by the mathematics educators, researchers, and psychologists. This is one way to know how negative emotions affect students' metacognitive dimensions and their performance in school.

To enrich these findings, future researchers may consider longitudinal studies and other programs to elucidate more clearly the roles of negative academic emotions, metacognition, academic buoyancy to mathematical performance of the students. Psychological researchers are motivated to give emphasis to the negative academic emotions considering the outcomes of the study. Accurate psychological theories on how students' motivation, cognition, and learning outcomes affected by these negative academic emotions must be prioritized. For teachers who wanted to give their students an environment that is conducive to learning which also helps them to achieve their goals and have a higher level of learning, theoretical constructions may act as a support.

\section{REFERENCES}

[1] R. Pekrun, T. Goetz, W. Titz., \& R.Perry. Academic emotions in students' self-regulated learning and achievement: A program of qualitative and quantitative research. Educational Psychologist, Volume. 37, No. 2, pp. 91-105, 2002.

[2] R. Pekrun and L. Linnenbrink-Garcia. International Handbook of Emotions in Education. New York: Routledge Routledge/Taylor \& Francis Group. Vol. 1. No.1, pp. 1-10, 2014.
[3] R. Pekrun, A.Elliot, \& M. Maier. Achievement goals and achievement emotions: Testing a model of their joint relations with academic performance. Journal of Educational Psychology, Vol.101, No.1 pp.583-597, 2009.

[4] A. Frenzel,. R.Pekrun., \& T. Goetz. Perceived learning environment and students' emotional experiences: A multilevel analysis of mathematics classrooms. Learning and Instruction Journal, Vol. 17, No.1, pp. 478-493. 2007.

[5] R. Pekrun, T. Goetz, W. Titz., \& R.Perry. Academic emotions in students' self-regulated learning and achievement: A program of qualitative and quantitative research. Educational Psychologist, Volume. 37, No. 2, pp. 91-105, 2002.

[6] R. Pekrun., T. Goetz, W. Titz., \& R.Perry. Academic emotions in students' self-regulated learning and achievement: A program of qualitative and quantitative research. Educational Psychologist, Volume. 37, No. 2, pp. 91-105, 2002.

[7] R. Pekrun and L. Linnenbrink-Garcia. International Handbook of Emotions in Education. New York: Routledge Routledge/Taylor \& Francis Group. Vol. 1. No.1, pp. 1-10, 2014.

[8] R. Pekrun, A.Elliot, \& M. Maier. Achievement goals and achievement emotions: Testing a model of their joint relations with academic performance. Journal of Educational Psychology, Vol.101, No.1 pp.583-597, 2009.

[9] A. Frenzel,. R.Pekrun., \& T. Goetz. Perceived learning environment and students' emotional experiences: A multilevel analysis of mathematics classrooms. Learning and Instruction Journal, Vol. 17, No.1, pp. 478-493. 2007.

[10] R. Pekrun, T. Goetz, W. Titz., \& R.Perry. Academic emotions in students' self-regulated learning and achievement: A program of qualitative and quantitative research. Educational Psychologist, Volume. 37, No. 2, pp. 91-105, 2002

[11] K. Trezise and R. Reeve. Cognition-emotion interactions: patterns of change and implications for math problem solving.” Frontiers in Psychology Journal. Vol 5. No.1, pp. $1-10.2014$

[12] I. Lyons and S. Beilock. When math hurts: Math anxiety predicts pain network activation in anticipation of doing math.” Clinical Psychology. Vol 30 pp. 1-11, 2012.

[13] R. Pekrun, T. Goetz, W. Titz., \& R. Perry. Academic emotions in students' self-regulated learning and achievement: A program of qualitative and quantitative research. Educational Psychologist, Volume. 37, No. 2, pp. 91-105, 2002.

[14] A. Bernardo. I., M. Salanga, and J. Ouano. What is an academic emotion? Insights from Filipino bilingual students' emotion words associated with learning.” Journal of Instructional Psychology. Volume 33, No.3, pp. 194-321, 2009.

[15] A. Martin. Academic buoyancy and academic resilience: Exploring 'everyday' and 'classic' resilience in the face of academic adversity. School Psychology International, Vol. 34, No.5, pp. 488-500, 2013.

[16] A. Martin, P. Ginns, M. Brackett, L. Malmberg, and J. Hall. Academic buoyancy and psychological risk. Exploring 
reciprocal relationships. Learning and Individual Differences. Vol. 27, 128-133, 2013.

[17] D. Putwain, L. Connors, W. Symes, \& E. Douglas-Osborn (2012). Is academic buoyancy anything more than adaptive coping? Anxiety, Stress, \& Coping. Vol 25, No.3, pp. 349-358, 2012.

[18] A. Martin, S. Colmar, L. Davey, \& H. Marsh. Longitudinal modelling of academic buoyancy and motivation: Do the 5Cs hold up over time?” British Journal of Educational Psychology, Vol.80, pp. 473-496, 2010.

[19] R. Pekrun, T. Goetz, A. Frenzel, P. Barchfeld, \& R. Perry. Measuring emotions in students' learning and performance: The achievement emotions questionnaire (AEQ). Contemporary Educational Psychology, Vol. 36, No.1, pp. 36-48, 2011

[20] B. Weiner. The development of an attribution-based theory of motivation: A history of ideas. Educational Psychologist Journal, Vol. 45, No.1, pp. 28-36, 2010.

[21] M. Spada, A. Nikčević, G. Moneta, \& J. Ireson. (2006). Metacognition as a mediator of the effect of test anxiety on surface approach to studying.” Educational Psychology, Vol 26, No. 1, pp. 1-10, 2006.

[22] E. Linnenbrink, and P. Pintrich. Multiple pathways to learning and achievement: The role of goal orientation in fostering adaptive motivation. Educational Psychology. Academic Press, pp 195-227, 2000.

[23] J. Turner, P. Thorpe, \& D. Meyer. Students' reports of motivation and negative affect: A theoretical and empirical analysis. Journal of Educational Psychology, Vol. 90, No. 4, pp. 758-771, 1998.

[24] K. Tajrishi, S. Mohammadkhani, \& F. Jadidi. Metacognitive beliefs and negative emotions. Procedia - Social and Behavioral Sciences, Vol 30. No.1, pp. 530 - 533, 2011.

[25] G. Ozsoy. An investigation of the relationship between metacognition and mathematics achievement. International Electric Journal of Elementary Education, Vol. 1 No.2, pp. 69-83, 2011.

[26] D. Pilot and B. Hungler. Nursing research: principles and methods. Philadelphia: JB Lippincott Company, pp.1-10, 1999

[27] A. Martin, S. Colmar, L. Davey, \& H. Marsh. Longitudinal modelling of academic buoyancy and motivation: Do the 5Cs hold up over time? British Journal of Educational Psychology, Vol. 80, pp. 473-496, 2010.

[28] A. Wells and S. Cartwright-Hatton. A short form of the Metacognitions Questionnaire: Properties of the MCQ-30.” Behaviour Research and Therapy, 2004.

[29] S. Coutinho. The relationship between goals, metacognition, and academic success.Educate, The Journal of Doctoral Research in Education, Vol. 7, No. 1, pp. 39-47, 2007.

[30] F. Peixoto, L. Mata, V. Monteiro, C. Sanches and R. Pekrun. The Achievement Emotions Questionnaire: Validation for Pre-Adolescent Students, European Journal of Developmental Psychology, Vol. 12, No. 4. Pp. 472-481, 2015.

[31] A. Young and J. Fry (2008). Metacognitive awareness and academic achievement in college students. Journal of the
Scholarship of Teaching and Learning, Vol. 8, No. 2, pp. 1-10, 2008.

[32] S. Nongtodu and Y. Bhutia, Y. Metacognition and its relation with academic achievement among college going students of Meghalaya. International Journal of Education and Psychological Research, Vol. 6, No 2, pp. 54-60, 2017.

[33] A. Martin, B. Papworth, P. Ginns, \& G. Liem. Boarding school, motivation and engagement, and psychological well-being: A large-scale investigation. American Educational Research Journal., Vol. 51, No.5, pp. 1007-1049, 2013.

[34] F. Villavicencio and A. Bernardo. Positive academic emotions moderate the relationship between self-regulation and academic achievement. British Journal of Educational Psychology, Vol.83, No.2, pp. 329-340. 2013.

[35] A. Martin and H. Marsh. Academic resilience and its psychological and educational correlates: A construct validity approach. Psychology in the Schools, Vol. 43, No.1, pp. 267-282, 2006.

[36] M. Tugade and B. Fredrickson, B.L. (2011). Resilient individuals use positive emotions to bounce back from negative emotional experiences. Journal of Personality and Social Psychology, Vol. 86, No. 2, pp. 320-333, 2011.

[37] R. Pekrun, T. Goetz, W. Titz., \& R.Perry. Academic emotions in students' self-regulated learning and achievement: A program of qualitative and quantitative research. Educational Psychologist, Volume. 37, No. 2, pp. 91-105, 2002

[38] J. Ruthig, R. Perry, S. Hladkyj, N. Hall, R. Pekrun, \& J. Chipperfield. Perceived control and emotions: Interactive effects on performance in achievement settings. Social Psychology of Education, Vol. 11, No.2, pp. 161-180, 2008.

[39] F. Villavicencio and A. Bernardo. Positive academic emotions moderate the relationship between self-regulation and academic achievement. British Journal of Educational Psychology, Vol.83, No.2, pp. 329-340. 2013.

[40] C. Kim and C. Hodges. Effects of an emotion control treatment on academic emotions, motivation and achievement in an online mathematics course. Instructional Science, Vol. 40, No.1, pp. 173-192, 2012.

[41] F. Villavicencio and A. Bernardo. Negative Emotions Moderate the Relationship Between Self-Efficacy and Achievement of Filipino Students. Psychological Studies, Vol. 58, No. 3, pp. 225-232, 2013.

[42] U. Lam, W. Chen, J. Zhang, \& T. Liang. It feels good to learn where I belong: School belonging, academic emotions, and academic achievement in adolescents." School Psychology International, Vol. 36. No.1, pp. 393-409, 2015.

[43] R. Pekrun, T. Goetz, W. Titz., \& R.Perry. Academic emotions in students' self-regulated learning and achievement: A program of qualitative and quantitative research. Educational Psychologist, Volume. 37, No. 2, pp. 91-105, 2002

[44] S. You, S. Hong, \& H. Ho, H. Longitudinal effects of perceived control on academic achievement. Journal of Educational Research, Vol. 104, No. 4, pp. 253-266, 2011.

[45] A. Martin, B. Papworth, P. Ginns, \& G. Liem. Boarding 
school, motivation and engagement, and psychological well-being: A large-scale investigation. American Educational Research Journal., Vol. 51, No.5, pp. 1007-1049, 2013.
[46] A. Martin and H. Marsh. Academic resilience and its psychological and educational correlates: A construct validity approach. Psychology in the Schools, Vol. 43, No.1, pp. 267-282, 2006. 